\title{
Chemical and Engineering Properties of Blended Cement Containing Micro- and Nano-silica
}

\author{
Hamdy El-Didamony Ahmed ${ }^{1}$, Berry Abd El-Ghani Sabrah ${ }^{2}$, Saleh Abd El-Aleem Mohamed ${ }^{2}$, \\ Nashwa Mohamed Mostafa ${ }^{3}$ \\ ${ }^{1}$ Chemistry Department, Faculty of Science, Zagazig University, Zagazig, Egypt \\ ${ }^{2}$ Chemistry Department, Faculty of Science, Fayoum University, Fayoum, Egypt \\ ${ }^{3}$ Faculty of Science, Fayoum University, Fayoum, Egypt
}

Email address:

saa09@fayoum.edu.eg (S. A. El-Aleem M.)

\section{To cite this article:}

Hamdy El-Didamony Ahmed, Berry Abd El-Ghani Sabrah, Saleh Abd El-Aleem Mohamed, Nashwa Mohamed Mostafa. Chemical and Engineering Properties of Blended Cement Containing Micro- and Nano-silica. American Journal of Chemical Engineering. Vol. 5, No. 5, 2017, pp. 111-121. doi: 10.11648/j.ajche.20170505.13

Received: August 31, 2017; Accepted: September 19, 2017; Published: November 3, 2017

\begin{abstract}
Nano-technology (NT) and nano-materials (NMs) has attracted considerable scientific attention, due to the new potential uses of nano-particles (NPs), which can change the concrete world. There is a great interest in replacing a long time used materials in concrete structure by NMs to improve the different properties of concrete. In this study, the hydration characteristics and microstructure of cement pastes and mortars with and without nano-silica (NS) were studied. Blended cement mix containing 10 mass, \% silica fume (SF) was prepared, then the cement mix was partially replaced by NS up 1.5 mass, \%. The results show that, NS increases the water of consistency and final setting time The values of chemically combined water, free lime, bulk density and compressive strength prove that, NS up to $1 \%$ seems to be an effective mineral additive for blending with OPC to improve its chemical and engineering properties. This is mainly attributed to that; NS behaves not only as filler to improve microstructure, but also as pozzolanic material (PZM). The formation of more hydrated silicates in presence of NS was confirmed by XRD, DTA, IR and SEM examinations. At 1.5 mass, $\%$ NS, the density and strength are reduced but still higher than those of 0.0 and $0.5 \%$ NS. Also, the results indicate that, the substitution of blended cement mix $(\mathrm{OPC}+10 \% \mathrm{SF})$ with 1 mass, \% NS gives a reasonable hydration characteristics and improved engineering properties more than those of 0.0 and $0.5 \%$ NS at all hydration ages up to 90 days. Therefore, this level of NS is suggested to be the most suitable replacement level.
\end{abstract}

Keywords: Microsilica, Nanosilica, Setting Times, OPC, Chemical Properties, Engineering Properties and Microstructure

\section{Introduction}

Nanotechnology (NT) is advanced technology, which deals with the synthesis of nanoparticles (NPs), and their applications. More recently, NT has attracted considerable scientific interest, due to the new potential uses of particles in nanometer $\left(10^{-9} \mathrm{~m}\right)$ scale; the advent of NT has brought in various types of nano-materials (NMs), which may have good applications in civil engineering, especially concrete production, due to their major effects: size effect, surface effect, and interface effect [1-4]. It was stated that [5], "the fineness of cement affects it's reactivity with water and generally the finer the cement the more rapidly it will react".
The role of NT in conceiving of innovative infrastructure systems has the potential to transform the civil engineering practice and dilate the vision of civil engineering [6]. NMs show unique chemical, physical and engineering properties different from those of the conventional materials. Indeed, NMs can change the concrete world, due to their properties at ultra-fine level [7]. There is a great interest in replacing a long time used materials in concrete structure by NMs to improve the engineering properties of concrete $[8,9]$. Also, If NMs are combined with traditional building materials; this may lead to production of building materials with unique 
properties and be very useful for construction industry.

NMs were used either to replace part of cement, producing ecological profile concrete or as admixtures in cement pastes [3]. In both cases, the addition of them improves the performance of cement; in fresh mixtures an improvement of rheological properties has been recorded [10] and in the hardened state, the compressive strength was increased [11, 12]. The nano-scale observations revealed the nanocrystallized structure of CSH $[13,14]$ and also NPs have been found to act as nuclei for cement phases, promoting their hydration $[15,16]$.

Nano-particles exhibit unique properties that develop a stronger, more durable concrete with favorable characteristics when added to concrete. Addition of NMs at the time of production of concrete can lead to significant improvements in the strength and life performance of concrete. One of the active areas of research dealing with cement and concrete is strength and durability of concrete containing NPs [17].

The role of NPs can be summarized as follows: i) NPs act as fillers in the empty spaces, ii) well distributed NPs act as crystallization centers (nuclei) of hydration products, increasing hydration rate, iii) NPs assist towards the formation of small sized $\mathrm{Ca}(\mathrm{OH})_{2}$ crystals and homogeneous clusters of CSH composition, and iv) NPs improve the structure of the transition zone between aggregates and paste [7]. Commonly used NMs are nano-silica (NS), nanoalumina (NA), nano-titania and nano-ferrit (NF). The most $\mathrm{NMs}$, which has a positive impact on engineering properties of cement concrete is NS. The performance of amorphous NMs is mainly influenced by chemical reaction at interface, enhancing the properties of concrete [18-20]. Nanosilica (NS) is typically a highly effective PZM. It is usually about 1000 times higher than the average cement particle. This has proven to be a superior mixture to improve and reduce the permeability of cement strength and durability. NS is in relation to the other components of silica and reduces the setting times of cement [21].

Addition of NS in cement paste and in concrete can lead to completely different effects. One is size effect, i.e. primarily based on their particle nature, which makes it useful as filling material and the second is the commerce pozzolanic activity of the cluster compounds [22]. NS in cement mortar not only increases the compressive strength, but also results in a finer pore structure, and then reduces overall permeability of hardened concrete [23-25].

Pozzolanic activity of NS and SF was previously studied
[26], and the results indicated that, the compressive strength development of pastes made with $\mathrm{Ca}(\mathrm{OH})_{2}$ and NS, the pozzolanic reaction rate of NS with $\mathrm{Ca}(\mathrm{OH})_{2}$ and the velocity of C-S-H formation showed marked increase over those of $\mathrm{Ca}(\mathrm{OH})_{2}$ with $\mathrm{SF}$. The bond strength as well as the bending strength of concrete incorporated with 3 mass, $\%$ NS increased more than those with SF, especially at early hydration ages.

Pozzolanic reactivity of NS was much greater than that of SF. The results suggest that, with a small amount of NS, the $\mathrm{Ca}(\mathrm{OH})_{2}$ crystal at the interface between hardened cement paste and aggregate at early ages may be effectively absorbed in High Performance Concrete (HPC).

In a previous work [27] it was reported that, NS powder caused pronounced improvements in the mechanical properties of mortars and concretes, most notably in compressive strength. Senff et al. [28] found that, fluidity; spreading and hardening time of the cement paste and mortar were reduced as the proportion of NS powder was increased.

The aim of this work is to investigate the chemical and physico-mechanical properties of blended cement containing micro- and nano-sized silica. The water of consistency, initial and final setting times were determined for each cement paste. Also, the values of chemically combined water, free lime, bulk density and compressive strength of hardened cement specimens were measured as a function of curing time up to 90-days. To follow up the hydration rate of the prepared samples, some selected hardened samples were investigated using the XRD, DTA, IR and SEM techniques.

\section{Materials and Experimental Details}

\subsection{Materials}

The starting materials used in this study were the ASTM Type (I) ordinary Portland cement (OPC), silica fume (SF) and nanosilica (NS). OPC with Blain surface area of $3000 \pm 50 \mathrm{~cm}^{2} / \mathrm{g}$ was provided from El-Masryah Cement Company, Egypt. The oxide analyses of OPC and SF obtained by X-ray fluorescence (XRF) spectrometry is summarized in Table 1. The mineralogical composition of OPC is listed in Table 2. SF with specific surface area of about $30.774 \pm 2 \mathrm{~m}^{2} / \mathrm{g}$ was supplied from Sika Chemical Company, Egypt. NS with average particle size, Blain surface area and purity percentage of about $15 \mathrm{~nm}, 50 \mathrm{~m}^{2} / \mathrm{g}$ and $99.9 \%$, respectively.

Table 1. Chemical Oxide Analyses of OPC and SF (mass, \%).

\begin{tabular}{lllllllllll}
\hline Oxides & $\mathbf{S i O}_{2}$ & $\mathbf{A l}_{2} \mathbf{O}_{3}$ & $\mathbf{F e}_{2} \mathbf{O}_{3}$ & $\mathbf{C a O}$ & $\mathbf{M g O}$ & $\mathbf{S O}_{3}$ & $\mathbf{N a}_{\mathbf{2}} \mathbf{O}$ & $\mathbf{K}_{\mathbf{2}} \mathbf{O}$ & $\mathbf{L}$. O. I & Total \\
\hline $\mathrm{OPC}$ & 19.30 & 3.94 & 3.80 & 62.67 & 1.90 & 3.22 & 0.44 & 0.39 & 3.04 & 99.70 \\
$\mathrm{SF}$ & 94.81 & 0.16 & 0.84 & 0.89 & 0.49 & 0.08 & 0.05 & 0.20 & 2.43 & 99.95 \\
\hline
\end{tabular}

Table 2. Mineralogical Composition of OPC.

\begin{tabular}{llll}
\hline Compound & Chemical formula & Abbreviation & Content, \% \\
\hline Tri-calcium silicate & $3 \mathrm{CaO} . \mathrm{SiO}_{2}$ & $\mathrm{C} 3 \mathrm{~S}$ & 66.08 \\
Di-calcium silicate & $2 \mathrm{CaO} . \mathrm{SiO}_{2}$ & $\mathrm{C} 2 \mathrm{~S}$ & 5.5 \\
Tri-calcium aluminate & $3 \mathrm{CaO} . \mathrm{Al}_{2} \mathrm{O}_{3}$ & $\mathrm{C} 3 \mathrm{~A}$ & 4.02 \\
Tetra-calcium aluminoferrite & $4 \mathrm{CaO} . \mathrm{Al}_{2} \mathrm{O}_{3} \cdot \mathrm{Fe}_{2} \mathrm{O}_{3}$ & $\mathrm{C} 4 \mathrm{AF}$ & 11.55 \\
\hline
\end{tabular}




\subsection{Experimental Details}

\subsubsection{Preparation of Cement Pastes and Mortars}

Nano-silica was synthesized according to the following procedure: a desired amount of $\mathrm{Na}_{2} \mathrm{SiO}_{3}$ solution was diluted with distilled water; the solution stirred for $15 \mathrm{~min}$, and then precipitated using diluted $\mathrm{HCl}$. The precipitate was filtered, washed several times with distilled water until complete removal of $\mathrm{NaCl}$ from the precipitate, and then the precipitate was dried overnight. To decrease the particle size of the prepared powder, it was milled by ball mill $(600 \mathrm{rpm})$ for 10 hours [29]. The amorphous nature of NS was verified using XRD and TEM techniques (Figures $1 \& 2$ ). OPC was partially substituted with NS up to 1.5 mass, \%. Each dry mix was blended in a steel ball mill using five balls for 1 hour in order to attain complete homogeneity. The cement blends were mixed in a rotary mixer. NS-particles are not easy to disperse uniformly in water, due to their high surface energy. Accordingly, the mixing was performed as follows: a) NS was stirred with $25.0 \%$ of the required water for standard consistency at high speed of $120 \mathrm{rpm}$ for $2 \mathrm{~min}$., b) the cement and the residual amount of mixing water were added to the mixer and homogenized at medium speed $(80 \mathrm{rpm})$ for another 2 min., c) the mixture was allowed to rest for 90 second, and then mixed for $1 \mathrm{~min}$ at $120 \mathrm{rpm}$ and d) the paste was manually placed, pressed and homogenized in stainless steel moulds. After the top layer was compacted, the top surface of the mould was smoothened by the aid of thin edged trowel. For preparation of mortars, the sand was added gradually in step b) and mixed at medium speed for additional $30 \mathrm{sec}$. The mortars were prepared according to ASTM (C109-93) by mixing 1 part of cement and 2.75 parts of sand proportion by weighing with water content sufficient to obtain a flow of $110 \pm 5$ with 25 drops of the flowing table [30-32]. Freshly prepared cement mortars were placed in $50 \times 50 \times 50 \mathrm{~mm}$ cubic moulds into two approximately equal layers manually compacted and pressed until a homogeneous specimen was obtained. The moulds were vibrated for a few minutes to remove any air bubbles and to give a better compaction. The mix compositions of the prepared blends are shown in Table 3.

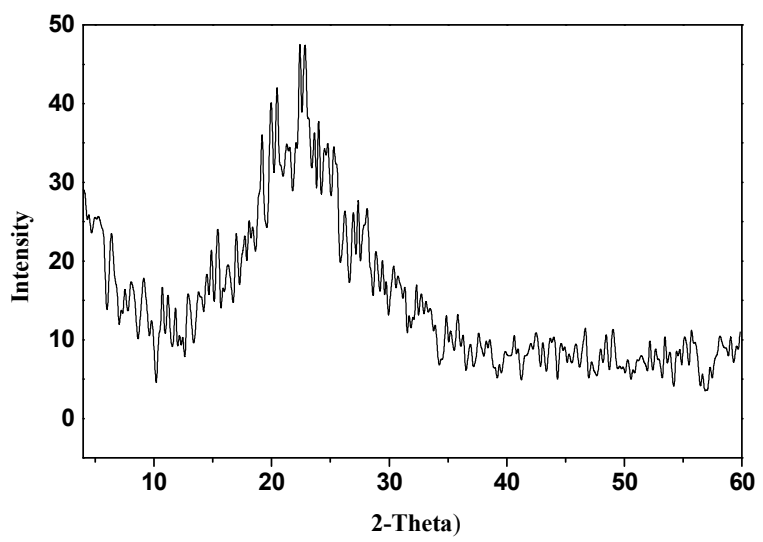

Figure 1. XRD Pattern of Nano-silica.
Table 3. Mix Composition of Blended Cements, (mass, \%).

\begin{tabular}{lll}
\hline Mix No. & $(\mathbf{O P C}+\mathbf{1 0} \% \mathbf{S F})$ & N. $\mathbf{S}$ \\
\hline M0 & 100 & 0 \\
M1 & 99.5 & 0.5 \\
M2 & 99 & 1 \\
M3 & 98.5 & 1.5 \\
\hline
\end{tabular}

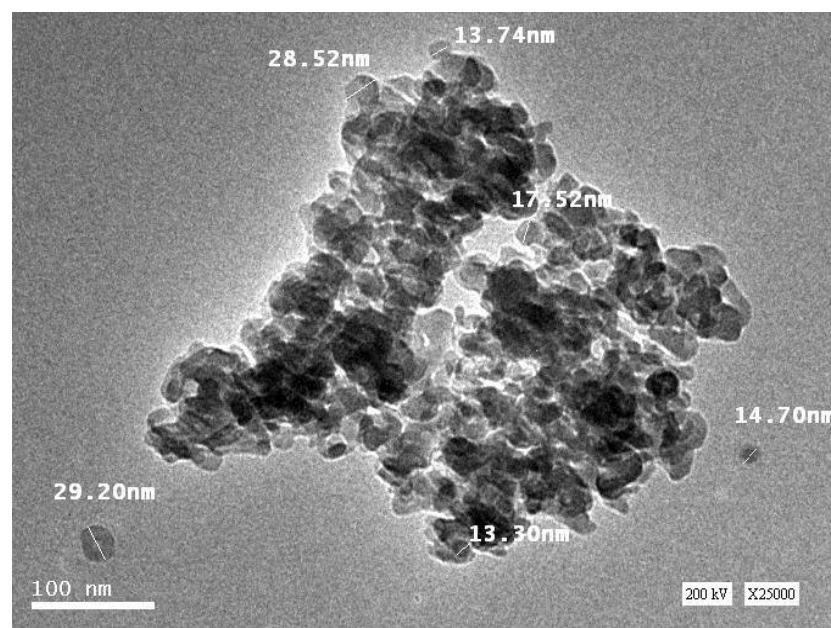

Figure 2. TEM Photograph of Nano-silica.

\subsubsection{Determination of Water of Consistency and Setting Times}

The required water of standard consistency gives a paste which permitted the settlement of the Vicat plunger $(10 \mathrm{~mm}$ in diameter) to a point $5-7 \mathrm{~mm}$ from the bottom of the Vicat moulds. It was measured to get all specimens having the same workability. The required water of standard consistency and setting times for each mix were determined according to ASTM specification [33].

\subsubsection{Curing and Stopping of Hydration}

The specimens were cured in a humidifier $(100 \% \mathrm{R} . \mathrm{H})$ at room temperature $23 \pm 2{ }^{\circ} \mathrm{C}$ for 24 hours, then immersed in tap water until the time of testing. After the predetermined curing time, the hydration of cement pastes was stopped by pulverizing 10 grams of representative sample in a beaker containing methanol-acetone mixture (1:1), and then mechanically stirred for 1 hour. The mixture was filtered through a gouch crucible, G4 and washed several times with the stopping solution, then with ether. The solid was dried at $70^{\circ} \mathrm{C}$ for 1 hour to complete evaporation of alcohol, then collected in polyethylene bags; sealed and stored in desiccators for analysis [34].

\subsubsection{Determination of Combined Water}

The chemically combined water content (Wn, \%) is used as an indication for the degree of cement hydration. $\mathrm{Wn}$ is that portion retained in the sample after the free water is removed. The $\mathrm{Wn}, \%$ is considered as the percent of ignition loss of the dried sample (on the ignited weight basis). Approximately 2 grams of the pre-dried sample were ignited at $1000^{\circ} \mathrm{C}$ for 1 hour. The results of $\mathrm{Wn}, \%$ were corrected for the water of free lime present in each sample [35]. 


\subsubsection{Free Lime Determination}

The free lime content of each hydrated cement paste was estimated by the following method, the sample $(0.5 \mathrm{~g})$ was poured in $40 \mathrm{ml}$ of a glycerol-ethanol mixture $(1: 5 \mathrm{v} / \mathrm{v})$, together with a small amount of anhydrous $\mathrm{BaCl}_{2}(0.5 \mathrm{~g})$ as a catalyst, and phenolphthalein ( $\mathrm{Ph} \mathrm{Ph})$ as an indicator. This mixture was kept in a conical flask, fitted with an air reflux, heated on a hot plate for 30 minutes (the color becomes pink). The contents of the flask were titrated with a standardized alcoholic ammonium acetate solution until the pink color just disappeared. Heating was again affected, and if the pink color reappears, the titration was completed with ammonium acetate solution until no further appearance of pink color occurs up on heating [36]. The free lime percentage was calculated as follow:

$$
\mathrm{CaO}, \%=[(\mathrm{W} 1 \times \mathrm{V}) / \mathrm{W}] \times 100, \mathrm{~W}=\text { original weight }
$$

$\mathrm{W} 1$ = weight of $\mathrm{CaO}$ equivalent to amount of added alcoholic ammonium acetate, $\mathrm{V}=$ volume of ammonium acetate per $\mathrm{ml}$.

\subsubsection{Bulk Density and Compressive Strength Measurements}

The bulk density (BD) was carried out on cement pastes. Samples were suspended weighed in water and in air (saturated surface dry). Each measurement was conducted on at least three similar cubes of the same mix composition and curing time. Then, the density was calculated as described elsewhere [37].

For compressive strength determination according to (ASTM Designation: C-150, 2007) [38], a set of three cubes was tested on a compressive strength machine of SEIDNER, Riedinger, Germany, with maximum capacity of $2000 \mathrm{KN}$ force.

\subsubsection{X-ray Diffraction}

The powder method of X-ray diffraction (XRD) was adopted in the present study. For this, a Philips diffractometer PW 1730 with X-ray source of $\mathrm{Cu} k \alpha$ radiation $(\lambda=1.5418$ $\AA)$ was used. The scan step size was $2 \theta$, the collection time $1 \mathrm{~s}$, and in the range of $2 \theta$ from 5 to 650 . The X-ray tube voltage and current were fixed at $40 \mathrm{KV}$ and $40 \mathrm{~mA}$ respectively. An on-line search of a standard database (JCPDS database) for X-ray powder diffraction pattern enables phase identification for a large variety of crystalline phases in a sample [39].

\subsubsection{Infrared Spectroscopic Analysis}

FTIR spectroscopic analysis was carried out to investigate the hydration products. The samples were prepared using alkali halide pressed disk technique as it gives a further reduction in scattering. Exactly $2 \mathrm{mg}$ of the sample was interground with $198 \mathrm{mg}$ of potassium bromide $(\mathrm{KBr})$ in agate mortar to produce a homogeneous mixture. The formed mixture was pressed under vacuum to give a transparent disk of $1.0 \mathrm{~cm}$ in diameter. Transfer the $\mathrm{KBr}$ disk to a sample holder and place it in the spectrometer. The FTIR spectral analysis was recorded from $\mathrm{KBr}$ disks using Mattson Gensis
FTIR spectrometer in the range from 400 up to $4000 \mathrm{~cm}^{-1}$ [40].

\subsubsection{Differential Thermal Analysis}

The DTA was carried out in air using a DT-30-Thermal Analyzer Shimadzu Co., koyoto, Japan. Calcined alumina was used as inert material, about $50 \mathrm{mg}(76 \mu \mathrm{m})$ of each of the finely ground hydrated cement pastes was housed in a small platinum-rhodium crusible. A uniform heating rate was adopted in all experiments at $20^{\circ} \mathrm{C} / \mathrm{min}$.

\subsubsection{Microstructure Examination}

The microstructures of some selected samples were investigated by FEI Inspect S ESEM Holland. Backscattered electron (BSE) imaging was used to study the samples without coating.

\section{Results and Discussion}

\subsection{Water of Consistency and Setting Times}

The variations of water of standard consistency (w/c, \%) of the investigated cement pastes are graphically represented in Figure 3. It obvious that, the water demand increases with $\mathrm{NS} \%$. The increase in water demand is attributed to the acceleration of hydration process of cement clinker phases under the effect of high fineness and surface energy of NS particles [41-44]. Thus the specimens containing NS require more water to rapid formation of hydration products [27].

The variations of the initial and final setting times (IST\&FST) of the investigated cement pastes with NS\% are plotted in Figure 4. It can be seen that, IST decreases and FST increases with NS content. The decrease of IST is mainly due the acceleration of cement hydration under the effect NS, leading to the formation of excessive amounts of $\mathrm{CSH}$, which fill up some of open pores originally filled with water that accelerates the setting. The increase of FST is attributed to the high water demand for standard consistency in presence of NS [3].

\subsection{Combined Water Contents}

The degree of cement hydration can be measured from the combined water $(\mathrm{Wn})$ and free lime (FL) contents. Figure 5 indicates the variations of combined water content of hydrated cement pastes up to 90 days as a function of $\mathrm{NS} \%$. It is apparent that, $\mathrm{Wn} \%$ increases with curing time for all hydrated cement pastes. This is essentially due to the continuous hydration of cement clinker phases, leading to the formation of more hydrated products. The values of $\mathrm{Wn} \%$ increase with NS content from 0.5 to $1.5 \%$ with two different rates, the first $(0.5-1 \%)$ is faster than the second $(>1 \%)$. After $1 \% \mathrm{NS}$, the $\mathrm{Wn} \%$ decreases, but still more than those containing 0.0 and $0.5 \%$ NS. The increase of $\mathrm{Wn} \%$ with $\mathrm{NS} \%$ seems to be due to two factors work together, the high water demand and pozzolanic action of NS. Nano-silica reacts with the liberated lime from the hydration of cement clinker phases, leading to the formation of additional and excessive hydrated products with high water contents, such 
as $\mathrm{CSH}, \mathrm{CAH}$ and $\mathrm{CASH}$. The results also show that, NS accelerates the hydration of cement clinker phases, especially at early ages of hydration [43], beginning from the time of mixing up to 28 days.

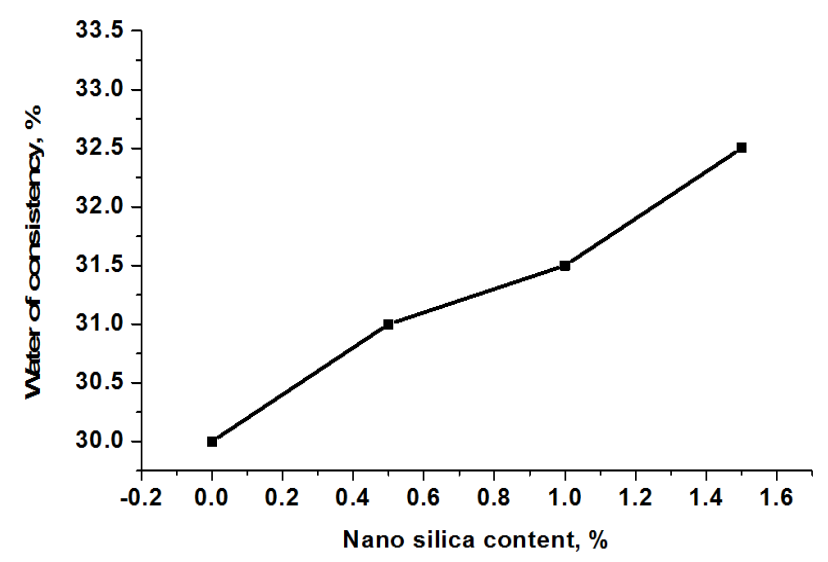

Figure 3. Water of Consistency of Cement Pastes with NS Content.

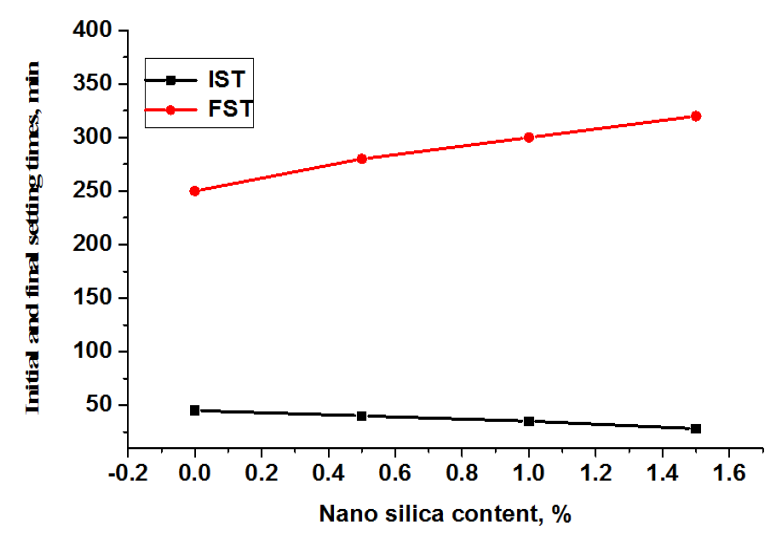

Figure 4. Setting Times of Cement Pastes with NS Content.

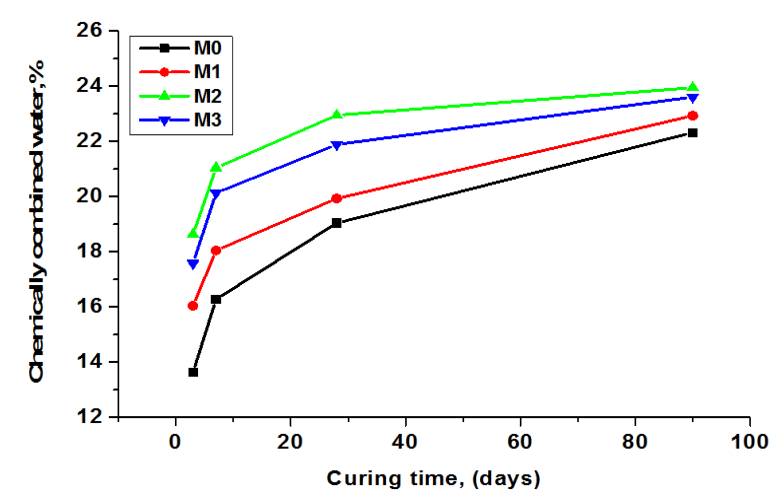

Figure 5. Chemically Combined Water Contents of the Hydrated Cement Pastes with NS\% and Curing Time.

\subsection{Free Lime}

The pozzolanic reaction of NS can be kinetically followed by monitoring the free lime contents at different curing times. The variation of free lime contents (FL \%) of cement pastes with different NS contents $(0-1.5 \%)$ and hydrated up to 90 days is shown in Figure 6 . The results indicate that, the values of FL decrease with curing time for all investigated cement pastes with and without NS. This is due to the pozzolanic reaction between the amorphous glassy silica (SF\&NS) with the free $\mathrm{Ca}(\mathrm{OH})_{2}$ liberated during calcium silicate hydration [3]. At a given hydration time, the FL content decreases with NS\%. This is due to the higher pozzolanic activity of NS comparing with SF.

\subsection{Bulk Density}

The bulk density (BD) values of cement pastes with different NS contents (0.0-1.5\%) and hydrated up to 90 days are graphically represented in Figure 7 . The results show that, the bulk density increases with curing time for all hydrated cement pastes, due to the continuous hydration of cement phases, leading to the formation and accumulation of successive amounts of hydrated silicates $(\mathrm{CSH})$ and aluminosilicates (CASH), which tends to increase the gel/space ratio as well as the bulk density $[34,45]$, leading to the formation of uniform and compact microstructure. The $\mathrm{BD}$ value increases with NS percentage up to 1 mass, $\%$, and then decreases at $1.5 \%$, but still higher than those containing 0.0 and $0.5 \%$ NS. This can be interpreted as follows [27]: Suppose that NS particles are uniformly dispersed in cement paste and each NS-particle is contained in a cube pattern, therefore the distance between NS-particles can be determined. After the hydration begins, the hydration products diffuse and envelop NS particles as kernel [46]. If the NS content and the distance between them are appropriate, the crystallization will be controlled to be a suitable state through restricting the growth of $\mathrm{Ca}(\mathrm{OH})_{2}$ crystals. Moreover, the NPs located in cement paste as kernel can further promote cement hydration, due to their high activity. This makes the size of $\mathrm{Ca}(\mathrm{OH})_{2}$ crystals smaller and the cement matrix more homogeneous and compact. Consequently, the pore structure is improved. With increasing the NS content more than $1 \%$, the improvement on the pore structure of cement paste is weakened, but still more better than those of 0.0 and $0.5 \% \mathrm{NS}$. This can be due to that, the distance between NPs decreases with increasing the content of nanoparticles, and $\mathrm{Ca}(\mathrm{OH}) 2$ crystals cannot grow up enough due to limited space and the crystal quantity is decreased, which leads to the decrease of crystal to strengthening gel ratio. Therefore, the shrinkage and creep of cement matrix are increased [47].

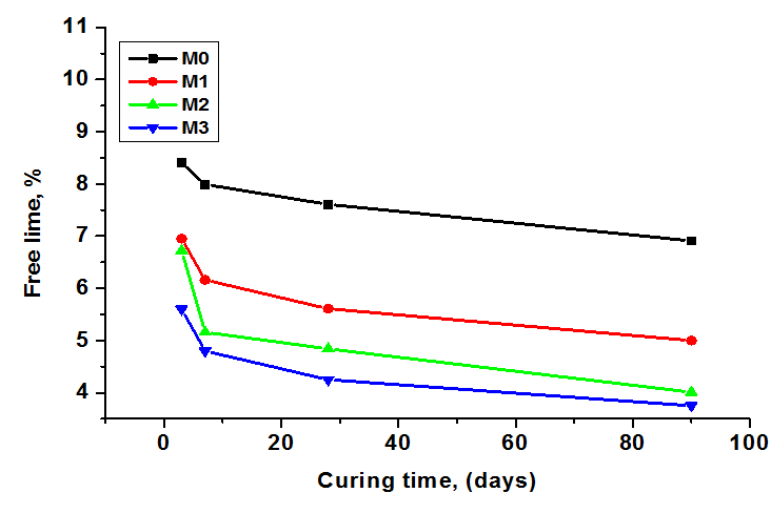

Figure 6. Free Lime Contents of the Hydrated Cement Pastes with NS\% and Curing Time. 


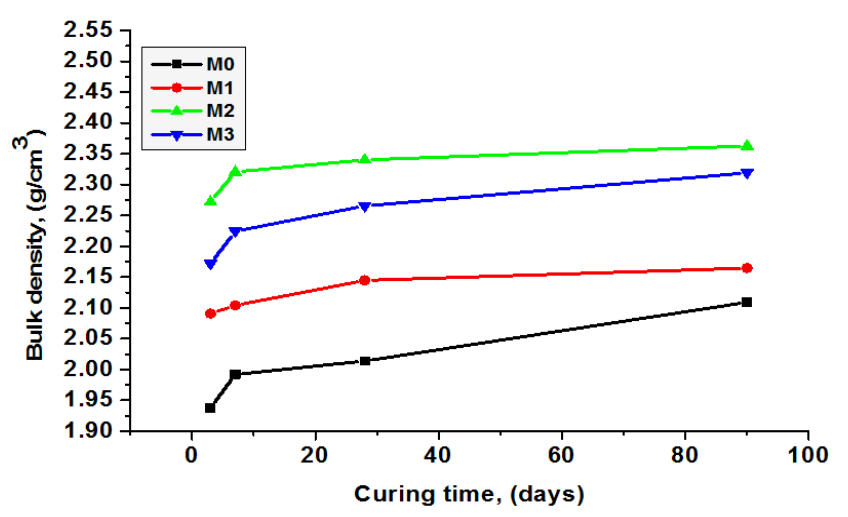

Figure 7. Bulk Density Values of the Hardened Cement Pastes with NS Content and Curing Time.

\subsection{Compressive Strength}

The effect of NS\% on the compressive strength values of hydrated cement mortars up to 90 days is graphically represented in Figure 8. It is clear that, the compressive strength values increase with curing time for all hydrated cement pastes, due to the continuous hydration and formation of excessive amounts of hydration products. These products accumulate in water filled pores to form a more compact body [45]. The results also indicate that, the compressive strength of the investigated mortars increases with NS content up to $1 \%$, and then decreases at $1.5 \%$, but still more than those containing 0.0 and $0.5 \%$ NS. The improvement of compressive strength in presence of NS up to $1 \%$ is attributed to that, NS behaves not only as a filler to improve the microstructure of cement mortar, but also as an activator to promote pozzolanic reaction. Both the nucleation and pozzolanic effects of NS lead to more accumulation and precipitation of hydration products in the open pore volume, leading to the formation of uniform, dense and compact microstructure. Consequently the bulk density and compressive strength increase with NS up to $1 \%$. The decrease of compressive strength at $1.5 \%$ NS seems to be due to the decrease of the distance between NS-particles with $\mathrm{NS} \%$. Therefore, $\mathrm{Ca}(\mathrm{OH})_{2}$ crystals cannot grow up enough due to the limited space and the crystal quantity is decreased, which leads to the reduction of crystal/gel ratio [47], thus the bulk density and compressive strength are relatively decreased.

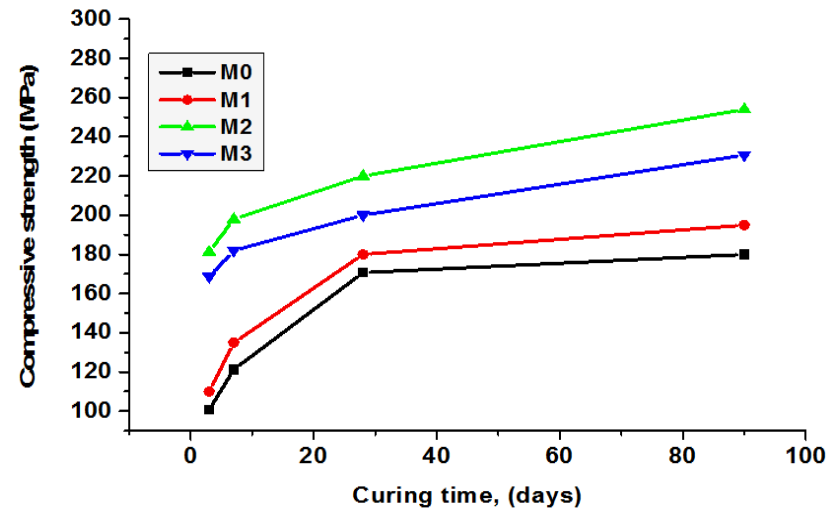

Figure 8. Compressive Strength of the Hardened Cement Pastes with NS Content and Curing Time.

\subsection{Interpretation of XRD Results}

Figure 9 represents XRD patterns of cement pastes containing $1 \%$ NS and hydrated at different curing times up to 90 days. The results indicate that, the peaks of $\mathrm{Ca}(\mathrm{OH})_{2}$ and anhydrous silicates decrease with curing time in contrast with the peak of Tobermorite like phase (CSH). This seems to be due to the hydration progress as well as the pozzolanic reaction of SF and NS with the liberated Portlandite, leading to the formation of additional amounts of hydrated silicates. Also, the calcite $\left(\mathrm{CaCO}_{3}\right)$ peak increases with curing time, due to the carbonation of hydration products. It is also clear that, the peaks related to formation of the hydration products shifts to appear at earlier curing times, indicating, the positive effect of NS-particles on the formation of both Portlandite and Tobermorite phases at early hydration ages [27].

The X-ray diffractograms of hydrated cement pastes with and without NS for 28 days are shown in Figure 10. It is clear that, the all hydrated cement mixes show Portlandite $\mathrm{Ca}(\mathrm{OH})_{2}$, Tobermorite $(\mathrm{CSH})$ and anhydrous silicates. Nanomodified cement mixes exhibit lower Portlandite peak intensity and higher Tobermorite peak intensity than the corresponding peaks in case of the control mix. The intensity of Portlandite peak decreases with NS content. The peaks of anhydrous silicate phases superpose with those of the hydrated silicates and decrease with NS content. But, the CSH has opposite manner to both Portlandite phase and anhydrous silicates. This is due to the pozzolanic reaction of NS with $\mathrm{Ca}(\mathrm{OH})_{2}$ formed from cement clinker hydration.

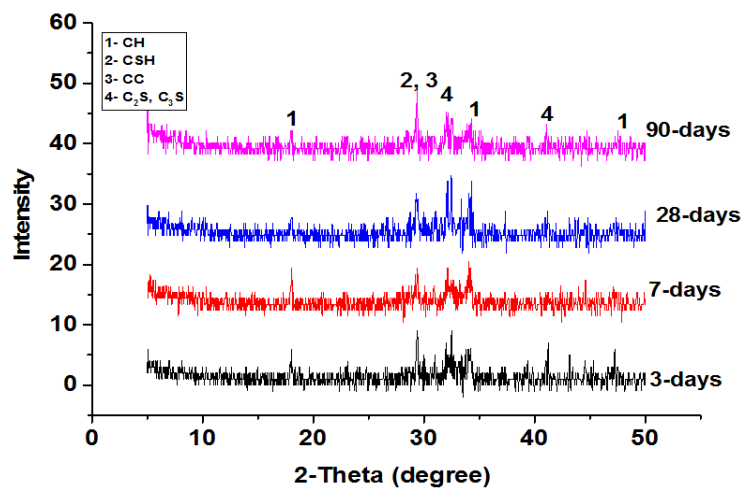

Figure 9. XRD-patterns of M2 at Different Curing Times.

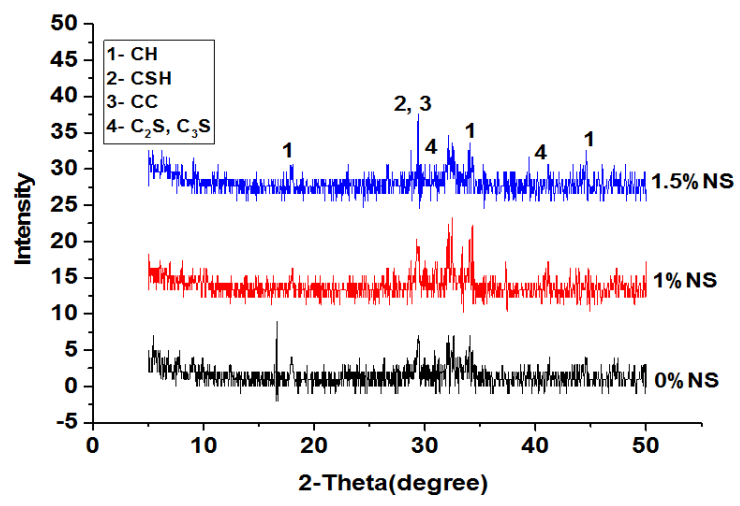

Figure 10. XRD-patterns of Hydrated MO, M2 and M3 at 28 Days. 


\subsection{IR Spectroscopy}

The effect of curing time up to 90 days on the hydration characteristics of cement pastes containing $1 \%$ NS can be seen from the IR spectra in Figure 11. The observed peak at about $3645 \mathrm{~cm}^{-1}$ is due to the $-\mathrm{OH}$ group of $\mathrm{Ca}(\mathrm{OH})_{2}$. Its intensity decreases with hydration time. This is due to that, NS acts as activator to promote the hydration of cement clinker phases, liberating free lime. Also, NS is a highly pozzolanic material (PZM) to react with the liberated Portlandite from cement hydration. With curing time, the pozzolanic effect of NS exceeds its accelerating action. Therefore, the rate of lime consumption becomes more than that of its production. The appeared band in the range 950$985 \mathrm{~cm}^{-1}$ is assigned to the formation of Tobermorite like phase (CSH) [50]. The broad band centered at about 3400 $\mathrm{cm}^{-1}$ and that at $1640-1650 \mathrm{~cm}^{-1}$ are due to stretching and bending vibration of water bound in the hydrated silicates. The band around $1480 \mathrm{~cm}-1$ is attributed to $\mathrm{C}-\mathrm{O}$ bond stretching of $\mathrm{CO}_{3}^{2-}$. The $\mathrm{CSH}$ peak has opposite pattern to that of $\mathrm{Ca}(\mathrm{OH})_{2}$.

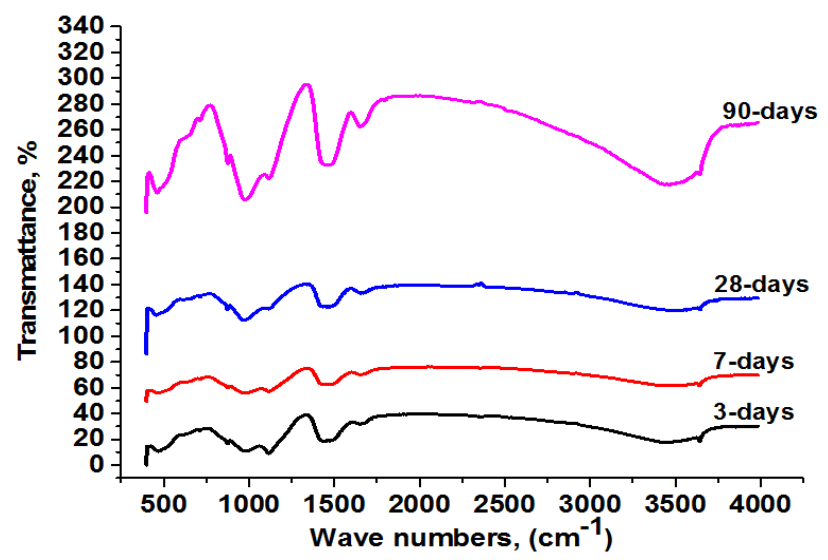

Figure 11. IR Patters of M2 at Different Curing Times.

Figure 12 represents the IR spectra of cement pastes with different NS\% and hydrated for 28 days. It is well known that, the phases of non-ordered structures cause the increase of band width and decreases its intensity. The results show the presence of peak at $3637-3640 \mathrm{~cm}^{-1}$ that can be assigned to the $-\mathrm{OH}$ band from Portlandite phase. This band is useful for diagnosis of the initiation of hydration process [48]. The intensity of that peak reduces with NS\%, due to the pozzolanic reaction of NS with the liberated Portlandite during cement phases hydration. The broad band at about $3448 \mathrm{~cm}-1$ and that observed at the range $1640-1650 \mathrm{~cm}-1$ are mainly due to the stretching and bending vibration of lattice water in the hydrated silicates and alumino-silicates (CSH and CASH)[49]. Their intensities increase and their widths decrease with NS\%, due to the pozzolanic action of NS, which accelerates the formation of more hydrated silicates. Also, the appeared band at $950-980 \mathrm{~cm}^{-1}$ is due to the formation of CSH [50]. The band at $1480 \mathrm{~cm}^{-1}$ is due to $\mathrm{C}-\mathrm{O}$ bond stretching of $\mathrm{CO}_{3}$, which result from the carbonation of hydrated silicates as well as the residual
$\mathrm{Ca}(\mathrm{OH})_{2}$. The exposure of cement pastes to $\mathrm{CO}_{2}$ results very quick carbonation [48]. Its intensity increases with NS\%. This may be due to that; NS behaves as activator to promote the hydration rate of cement phases. The observed band at $495 \mathrm{~cm}^{-1}$ is due to bending vibration of $\mathrm{Si}-\mathrm{O}$ bond in $\mathrm{SiO}^{2-}$ tetrahedral [51]. Its intensity increase with NS content, due to the above-mentioned reasons.

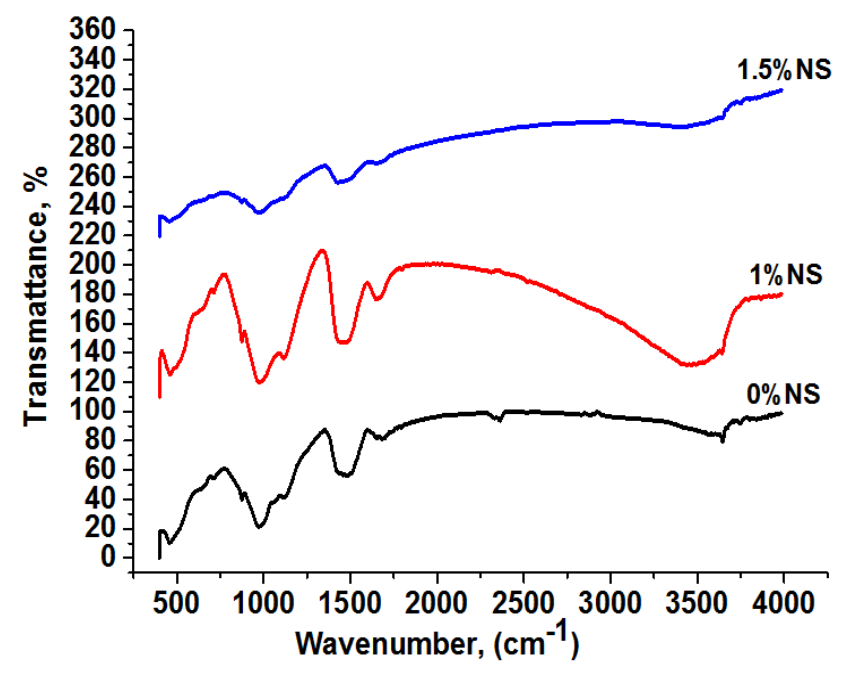

Figure 12. IR Patters of Hydrated M0, M2 and M3 at 28 Days.

\subsection{Differential Thermal Analysis (DTA)}

Figure 13 represents the DTA thermograms of $\mathrm{M}_{2}$ at different curing times up to 90 days. It can be seen that, the intensity of $\mathrm{CH}$ endotherm increases and shifted to higher dissociation temperature with curing time to 7 days, then decreases up to 90 days. Therefore, the area of $\mathrm{Ca}(\mathrm{OH})_{2}$ peak and its temperature range are reduced with curing time after 7 up to 90 days. The endothermic peak of CSH has opposite manner to that of Portlandite, because the more consumption of lime means more CSH formation.

The DTA results of cement mixes containing different NS percentages and hydrated at 28 days are graphically represented in Figure 14. Very small endothermic peaks appear at low temperatures up to $250^{\circ} \mathrm{C}$, may be due to the decomposition of hydrated silicates as Tobermorite like phase (CSH). The endothermic peak located at $477-480^{\circ} \mathrm{C}$ may be assigned to the dehydration of free $\mathrm{Ca}(\mathrm{OH})_{2}$ whereas the broad endotherm at $700-750^{\circ} \mathrm{C}$ is mainly related to the decomposition of calcite phase $\left(\mathrm{CaCO}_{3}\right)$ or carbonated $\mathrm{CSH}$. It is clear that, the $\mathrm{Ca}(\mathrm{OH})_{2}$ endothermic peak is occurred at lower temperature range than the normal. Also, its area decreases with NS\%. This is mainly due to the pozzolanic reaction of NS particles with free lime. The results of DTA analysis are in a good harmony with those of XRD, IR and chemical analyses.

\subsection{Microstructure Discussion}

To verify the mechanism predicted by the experimental results obtained in this work, SEM examinations were performed. Figure 15 represents the microstructure 
photographs of M2 at different curing times (3, 7, 28 and 90 days). The micrographs show increase of compaction and homogeneity of the internal microstructure with curing time for all hydrated mixes. This is principally due to the continuous hydration of cement clinker phases as well as the pozzolanic reaction of NS with free lime, leading to the formation of successive and additional amounts of hydrated products, which responsible for compaction and strength properties of cement paste.

Addition of NS was found to affect the hydration behavior of cement paste and leads to differences in the microstructure of the hardened cement paste. Figure 16 represents the microstructure photographs of M0, M2 and M3 at 28 days. The CSH gel existed in the form of 'stand-alone' clusters, lapped and jointed together by many needle hydrates. At the same time, $\mathrm{Ca}(\mathrm{OH})_{2}$ crystals were distributed among the cement paste in the microstructure of M0. But, the microstructures of the pastes containing NS, which are of higher strength than M0 revealed a pores filling with dense and compact structure, i.e., the texture of hydrated products was more dense and compact. Big crystals such as $\mathrm{Ca}(\mathrm{OH})_{2}$ are nearly absent, due to the pozzolanic reaction of NS with the lime liberated during cement clinker hydration, leading to the formation of more hydration products. Thus the number and size of calcium hydroxide $(\mathrm{CH})$ crystals are reduced. It is clear that, $1 \%$ NS gives cement paste with more uniform and denser microstructure than $1.5 \%$. The suggested mechanism that, the NS can improve the microstructure and consequently the strength of cement paste is illustrated as follows: When a small quantity of NS is uniformly dispersed in the cement paste, the hydrated products of cement will deposit on the nano-particles (NPs), due to their great surface area and high surface energy. The hydration products will grow to form conglomeration containing the NS-particles as 'nuclei'. Due to its high pozzolanic activity, the NS-particles located in the cement paste as nuclei will further activate and accelerate the hydration of cement clinker phases. The uniformly disperse situation of NS gives a good microstructure with uniformly distributed conglomeration. According to Wu's 'centroplasm' hypothesis, the aggregates, sands and other particles are considered as centroplasm that acts as skeleton, and gel as transmitter substance. The binding force between centroplasm and transmitter substance has an important effect on the strength of concrete [52]. The NS-particles distributing in cement paste as 'subcentroplasm' can tightly bond with the hydrated products around the interfacial transition zone (ITZ) between the NPs and hydrated products. On the other hand, the NPs among the hydrated products will prevent the crystal from growing, such as $\mathrm{Ca}(\mathrm{OH})_{2}$ and $\mathrm{AFm}$, and such fine crystals are favorable for the strengthening properties of cement paste [53-55]. Also, the NS-particles will fill pores to increase the strength. However, when NS cannot be well dispersed, as the case of its extensive content, the aggregating NS- particles will create weak zone, in form of voids. Consequently, the homogeneous microstructure cannot be formed, and low strength will be expected.

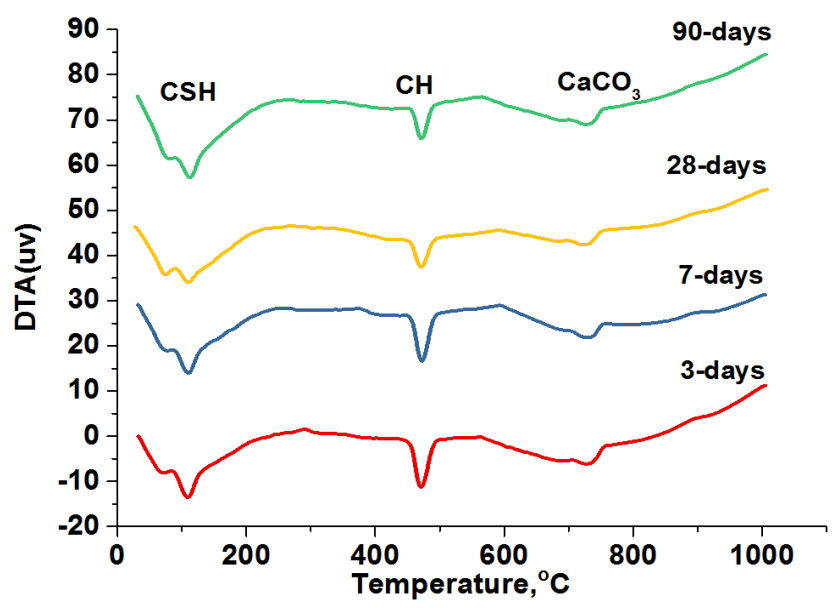

Figure 13. DTA-Thermographes of Hydrated M2 at Different Curing Times.

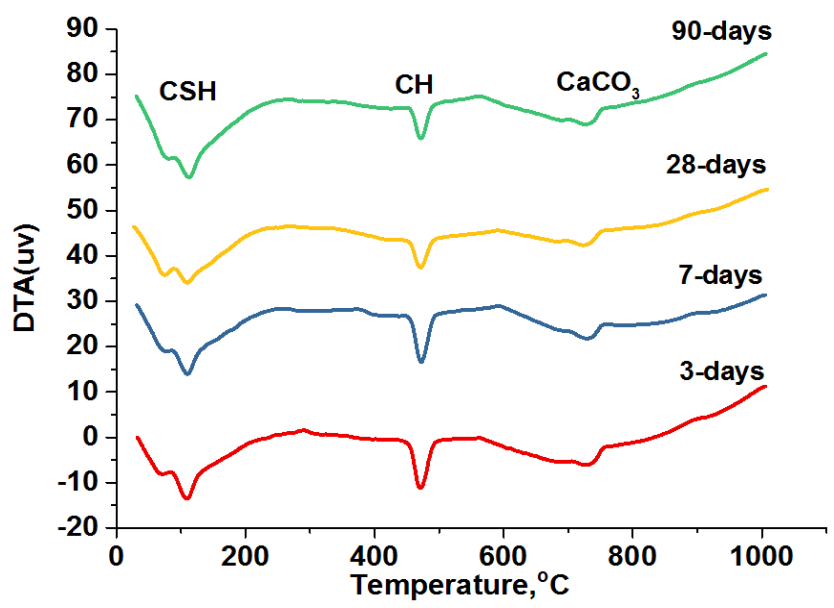

Figure 14. DTA-Thermographes of Hydrated Cement Pastes with Different NS\% at 28-days.

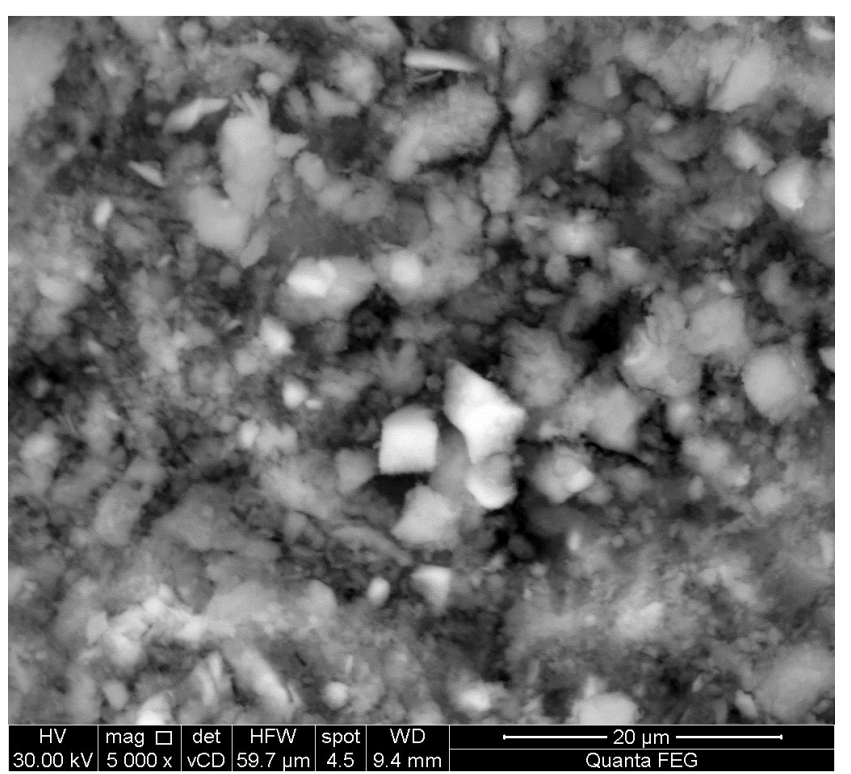

(3d) 


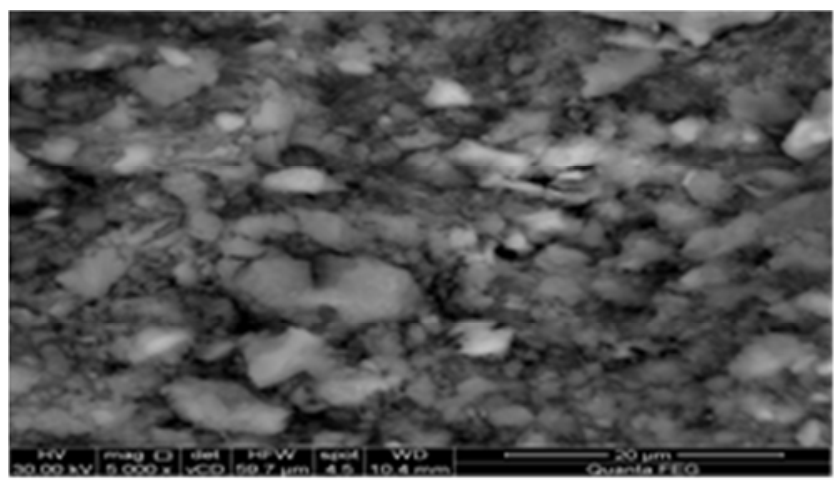

(7d)

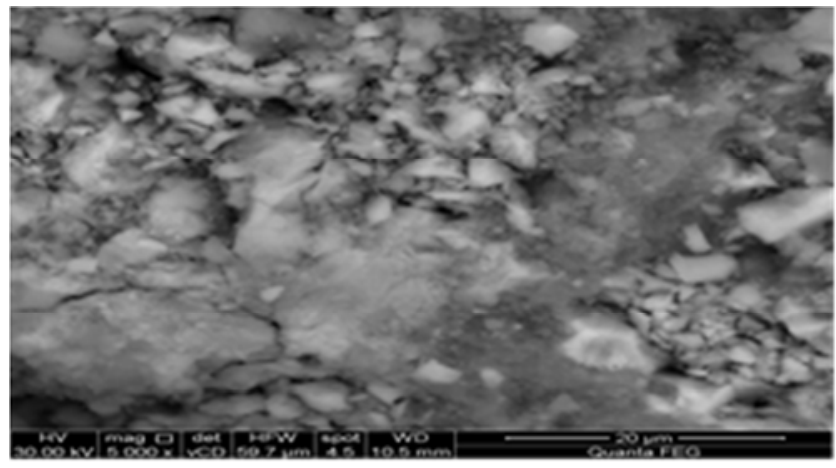

(28d)

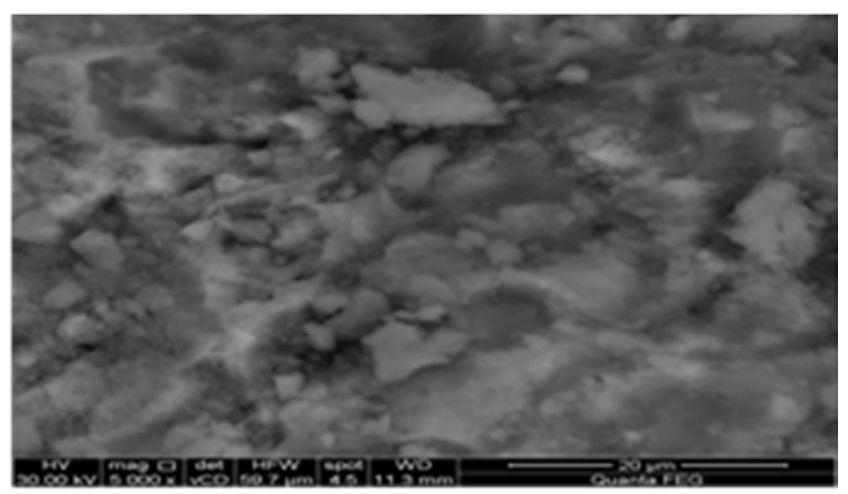

(90d)

Figure 15. SEM Photographs of Hydrated M2 at 3, 7, 28 and 90 Days.

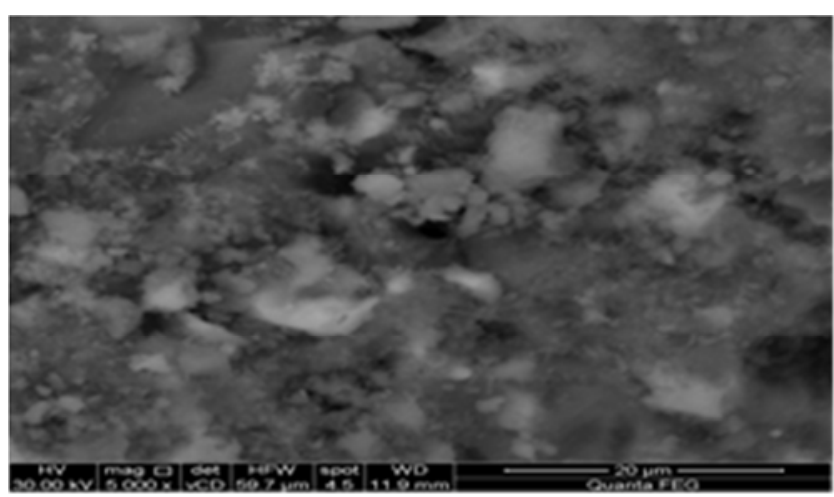

(M0)

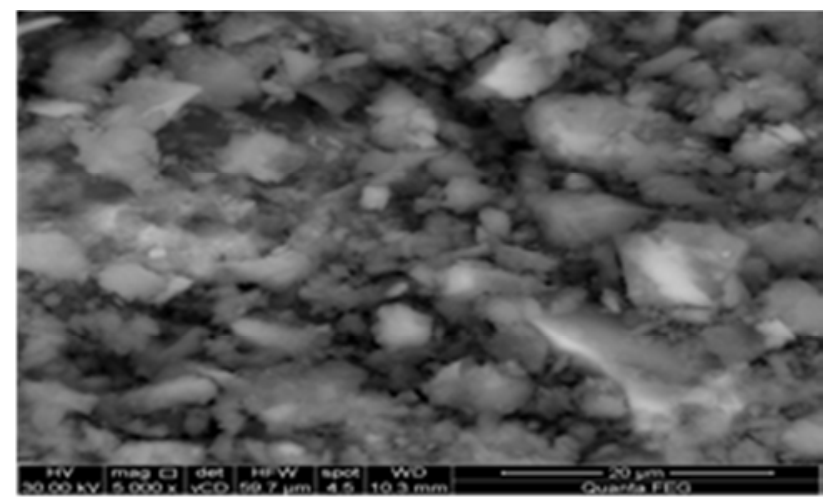

(M2)

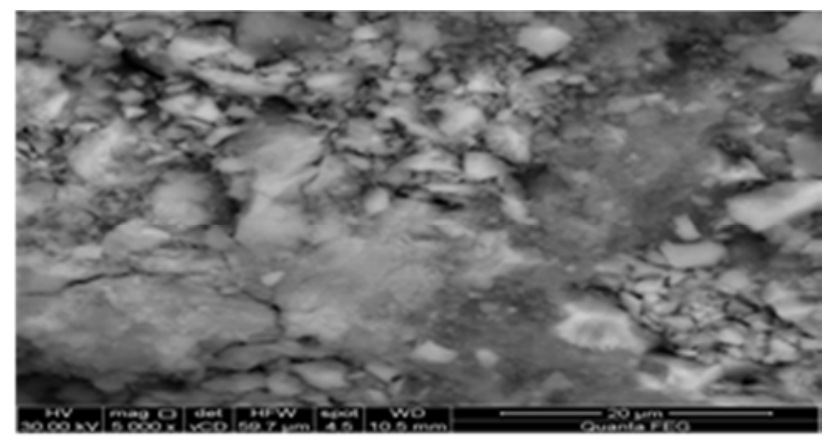

(M3)

Figure 16. SEM Photographs of Hydrated MO, M2 and M3 at 28 Days.

\section{Conclusions}

Based on the experimental results of this work, the following conclusions were drawn:

1. Nano-silica (NS) significantly increases the water demand for standard consistency, and consequently final setting time (FST). This seems to be controlled by the particle size distribution and high specific surface area of NS.

2. The free lime decreases with $\mathrm{NS} \%$, due the high pozzolanic action of NS.

3. Chemically combined water contents increase with $\mathrm{NS}, \%$. This is attributed to the pozzolanic reaction of NS with the lime liberated from cement hydration, leading to the formation of more hydrated products with higher water contents than that of $\mathrm{Ca}(\mathrm{OH})_{2}$.

4. The bulk density (BD), microstructure and consequently the mechanical properties of the investigated cement mortars are improved with NS up to $1 \%$, and then decreases at $1.5 \%$, but still higher than those containing 0.0 and $0.5 \%$ NS. With increasing the NS content more than $1 \%$, the improvement on the pore structure of cement paste is weakened, but still more better than those of 0.0 and $0.5 \%$ NS. This can be due to that, the distance between nano-particles decreases with increasing the content of nanoparticles, and $\mathrm{Ca}(\mathrm{OH})_{2}$ crystals cannot grow up enough due to limited space and the crystal quantity is decreased, which leads to the decrease of crystal to strengthening gel ratio.

5. The compressive strength values increase with curing time for all hydrated cement pastes, due to the continuous 
hydration and formation of excessive amounts of hydration products. These products accumulate in water filled pores to form a more compact body. More rapid formation of hydrated products in presence of nano- $\mathrm{SiO}_{2}$ was confirmed by XRD, DTA, IR and SEM examinations. Their results are in a good harmony with those of chemical and physicomechanical of the investigated mixes.

6 . The NS up to $1 \%$ proved to be an effective mineral additive for blending with Portland cement to improve its chemical and engineering properties.

7. The substitution of blended cement mix (OPC $+10 \% \mathrm{SF})$ with $1 \mathrm{wt} . \%$ NS gives a reasonable hydration characteristics and improved engineering properties more than those of 0.0 and $0.5 \% \mathrm{NS}$ at all hydration ages up to 90 days. Therefore, this level of NS is suggested to be the most suitable replacement level.

\section{References}

[1] L. G. Li, Z. H. Huang, J. Zhu, A. K. H. Kwan, H. Y. Chen, "Synergistic effects of micro-silica and nano-silica on strength and microstructure of mortar", Construction and Building Materials 140 (2017), pp. 229-238.

[2] F. Pacheco-Torgal, S. Miraldo, Y. Ding, J. A. Labrincha, Targeting HPC with the help of nanoparticles: an overview, Constr. Build. Mater., 38 (2013), pp. 365-370.

[3] Jo B. W, Kim C. H, Tae G. H, Park J. B. "Characteristics of cement mortar with nano- $\mathrm{SiO}_{2}$ particles". Constr. Build. Mater. 21(6); (2007), 1351-1355.

[4] H. A. Abdel-Gawwad, S. Abd El-Aleem, "Effect of Reactive Magnesia on the Properties of Alkali Activated Slag Cement Pastes", International Journal of Science and Research (IJSR), 4 (5), 2015, 1197-1204.

[5] Mehta PK. "Concrete, structure, properties and materials" Editor WJ. Hall; (1986).

[6] V. S. Mane, P. S. Yadav, Y. S. Dudhagamwar, P. S. Gawande, "Study on Nanotechnology in Civil Engineering Structures", International Advanced Research Journal in Science, Engineering and Technology.

[7] Li H., Xiao H, Yuan J., Ou J. "Microstructure of cement mortar with nano-particles" Composites: Part B 35, (2004), pp. 185-189.

[8] Givi A. N., Rashid. S. A, A. Aziz F. N, Salleh M. A. M "Experimental investigation of the size effects of $\mathrm{SiO}_{2}$ nanoparticles on the mechanical properties of binary blended concrete" Composites: Part B 41 (2010), pp. 673-677.

[9] Mahender B., Ashok B., "Effect of Nanosilica on the compressive strength of concrete", International Journal of Professional Engineering Studies, 8, 2 (2017).

[10] S. Abd. El. Aleem, M. Heikal, W. M. Morsi "Hydration characteristic, thermal expansion and microstructure of cement containing nano-silica", Constr. Build. Mater.; 59, 2014, 151-160.

[11] Senff L., Labrincha J. A, Ferreira V. M., Hotza D., and Repette W. L., Constr. Build. Mater. 23 (2009) 2487-2491.

[12] Qing Y., Zenan Z., Li S., and Rongshen C. "A comparative study on the pozzolanic activity between nano- $\mathrm{SiO}_{2}$ and silica fume" J Wuhan Univ. Technol. Matere Sci. Ed 21(3) (2008), pp. 153-7.

[13] Zyganitidis I., Stefanidou M., Kalfagiannis N., Logothetidis S. "Nano-mechanical characterization of cement-based pastes enriched with $\mathrm{SiO}_{2}$ nano-particles" Mat. Sci. Eng. B 176 (9); (2011), pp. 1580-1584.

[14] Ulm F. J., Vandamme M. "Probing nanostructure of C-S-H by micro- mechanics based indentation techniques" Editors: Bittnar Z., Bartos P. J. M., Nemecek J., Smilauer V., Zeman J. Nano-technology in Construction: Proceedings of the NICOM3 Prague; (2009), pp. 43-54.

[15] Quercia G., Brouwers H. J. H. "Application of nano-silica in concrete mixtures" 8th PhD Symposium in Kgs. Lyngby Denmark;( 2010).

[16] Corr D., Shah S. P. "Concrete materials science at the nanoscale" Applications of Nanotechnology in concrete Design Edited by Dhir R. K., Newlands M. D., Csetenyi L. J; (2005), pp. 1-12.

[17] Jemimah Carmichae M., Prince Arulraj G., "Strength and permeability studies on concrete with Nano-Cement", IJCIET, 8, (2017), pp. 132-139.

[18] Meral Oltulu., Remzi Sahin., "Single and combined effects of nano- $\mathrm{SiO}_{2}$, nano- $\mathrm{Al}_{2} \mathrm{O}_{3}$ and nano- $\mathrm{Fe}_{2} \mathrm{O}_{3}$ powders on compressive strength and capillary permeability of cement mortar containing silica fume", Materials Science and Engineering A., 528., (2011), pp. 7012-7019.

[19] Zhang P., Wana J., Wang K., Li Q., "Influence of nano-SiO on properties of fresh and hardened high performance concrete: A state-of-the-art review", Constr. Build. Mater., 148, (2017), pp. 648-658.

[20] Amr A. Essawy and S. Abd El. Aleem "Physico-mechanical properties, potent adsorptive and photocatalytic efficacies of sulfate resisting cement blends containing micro silica and nano- $\mathrm{TiO}_{2}$ ", Construction and Building Materials 52, 2014, 1-8.

[21] Heikal, M., El-Didamony, H., Sokkary, T. M. and Ahmed, I. A., "Behavior of composite cement pastes containing microsilica and fly ash at elevated temperature", Constr. Build. Mater., 38, (2013), pp. 1180-1190.

[22] Pokar Amitkumar R., Pokar Narendra R., "Application of Silica Fume and Nanosilica in Cement and Concrete - A Review", 3, 5, (2016), pp. 723-724.

[23] Haruehansapong S., Pulngern T., and Chucheepsakul S., "Effect of the particle size of nanosilica on the compressive strength and the optimum replacement content of cement mortar containing Nano-SiO 2 " Construction and Building Materials, 50, (2014), pp. 471-477.

[24] Zemei Wu, Kamal Henri Khayat, and Caijun Shi., "Effect of nano- $\mathrm{SiO}_{2}$ particles and curing time on development of fibermatrix bond properties and microstructure of ultra-high strength concrete", Cement and Concrete Research, 95, (2017), pp. 247-256.

[25] Sattawat Haruehansapong, Tawich Pulngern and Somchai Chucheepsakul., "Effect of Nanosilica Particle Size on the Water Permeability, Abrasion Resistance, Drying Shrinkage, and Repair Work Properties of Cement Mortar Containing Nano- $\mathrm{SiO}_{2}{ }_{2}$, Hindawi Advances in Materials Science and Engineering, (2017), 11 pages. 
[26] Qing, Y., Zenan, Z., Li, S. and Rongshen, C. A., "A comparative study on the pozzolanic activity between nano$\mathrm{SiO}_{2}$ and silica fume", J. Wuhan Univ. Technol. Mater. Sci., Ed. 21, (2006), pp. 153-157.

[27] Nazari A., Riahi S. "The effects of $\mathrm{SiO}_{2}$ nanoparticles on physical and mechanical properties of high strength compacting concrete" Compos. Part B: Eng. 42 (2011) 570578 .

[28] L. Senff, J. A. Labrincha, V. M. Ferreira, D. Hotza, W. L. Repette, Construct. Build. Mater., 23, (2009), pp. 2487-2491.

[29] S. Abd El-Aleem, and A. Ragab, "Physico-Mechanical Properties and Microstructure of Blended Cement Incorporating Nano-Silica" International Journal of Engineering Research \& Technology, 3 (2014), pp. 339-358.

[30] Abd-El-Eziz M. A. and Heikal M. "Hydration characteristics and durability of cements containing fly ash and limestone subjected to Qaron's Lake Water" Adv. Cem. Res., 21(3); (2009), pp. 91-99.

[31] M. Heikal, S. Abd El-Aleem, and W M. Morsi, "Characteristics of blended cements containing nano-silica" HBRC Journal (9) (2013), pp. 243-255.

[32] Magdy A. Abdelaziz, Saleh Abd El-Aleem and Wagih M. Menshawy, "Effect of fine materials in local quarry dusts of limestone and basalt on the properties of Portland cement pastes and mortars", International Journal of Engineering Research \& Technology (IJERT), 3(6), ( 2014), pp. 10381056 .

[33] ASTM Designation: C191, Standard method for normal consistency and setting of hydraulic cement, ASTM Annual Book of ASTM Standards, (2008).

[34] M. A. Abd-El. Aziz, S. Abd. El. Aleem, and M. Heikal "Physico-chemical and mechanical characteristics of pozzolanic cement pastes and mortars hydrated at different curing temperatures" Constr. Build. Mater. 26; (2012), pp. 310-316.

[35] H. El-Didamony, M. Abd-El. Eziz, and S. Abd. El. Aleem, Hydration and durability of sulfate resisting and slag cement blends in Qarons "Lake water”, Cem. Concr. Res., 35; (2005), pp. 1592-1600.

[36] H. W. Sufee, "Comprehensive studies of different blended cements and steel corrosion performance in presence of admixture", Ph.D. Thesis, Faculty of Science, Fayoum University, Fayoum, Egypt) 2007).

[37] Abd-El-Eziz M. A. and Heikal M. "Hydration characteristics and durability of cements containing fly ash and limestone subjected to Qaron's Lake Water" Adv. Cem. Res., 21(3); (2009), pp. 91-99.

[38] [38]ASTM C109, Strength test method for compressive strength of hydraulic cement mortars, (2007).

[39] Ramachandran V. S. "Thermal Analysis, in; Handbook of analytical techniques in concrete science and technology" Ramachandran V. S. and Beaudoin J. J. Eds., Noyes publications, New Jersey. ISBN: 0-8155; (2001), PP. 14731479.
[40] Errington R. J. "Advanced practical inorganic and metalorganic chemistry" Blackie Academic \& Professional, An Imprint Chapman \& Hall; (1997).

[41] Sobolev K., et al. "Engineering of $\mathrm{SiO}_{2}$ nano-particles for optimal performance in nano cement-based materials" Editors: Bittnar Z., Bartos P. J. M., Nemecek J., Smilauer V., Zeman J. Nanotechnology in Construction: Proceedings of the $\mathrm{NICOM}_{3}$ Prague; (2009), pp. 139-48.

[42] Bjornstrom J., Martinelli A., Matic A., Borjesson L. and Panas I. "Accelerating effects of colloidal nanosilica for beneficial calcium-silicate-hydrate formation in cement" Chemical Physic Letter, 392, (2004), pp. 242 - 248.

[43] Qing Y., Zenan Z. H., Deyu K. and Rongshen C. H. "Influence of nano- $\mathrm{SiO}_{2}$ addition on properties of hardened cement paste as compared with silica fume". Construction and Building Materials, 21, (2007), pp. 539-545.

[44] Li G. "Properties of high volume fly ash concrete incorporating nano $\mathrm{SiO}_{2}$ " Cem. Concr. Res. 34, (2004), pp. $1043-1049$.

[45] Abd El. Aziz M., Abd El Aleem S., Heikal M., El. Didamony H. "Effect of Polycarboxylate on Rice Husk Ash Pozzolanic Cement” Sil. Ind., 69, 9-10; (2004), pp. 73-84.

[46] Legrand C, Wirquin E. "Study of the strength of very young concrete as a function of the amount of hydrates formed-influence of superplasticizer" Mater. Struct.; 166, (1994), pp. 106-9.

[47] $\mathrm{Li} \mathrm{H}$, Zhang M, Ou J. "Flexural fatigue performance of concrete containing nanoparticles for pavement". Int. J. Fatigue; 29, (2007), pp. 1292-301.

[48] Bensted J., Applications of Infrared Spectroscopy to cement hydration, paper delivered at the Construction Materials Group and Institute of Materials Meeting on Techniques for Characterization of cement hydration, London (1994) Society of Chemical Industry.

[49] Gao X. F., Lo Y., Tam C. M. and Chung C. Y., "Analysis of the infrared spectrum and microstructure of hardened cement paste", Cem. Concr. Res., 29, (1999), pp. 805-812.

[50] Delgado A. H., Paroli R. M. and Beaudoin J. J., Comparison of IR techniques for the characterization of construction cement minerals and hydrated products, Applied Spectroscopy, 50(8); (1996), pp. 970-976.

[51] Lee, Chemistry of cement and concert London Arnold Ltd (2007).

[52] Ghabezloo Siavash, Sulem Jean, Saint-Marc Jérémie. The effect of undrained heating on a fluid-saturated hardened cement paste. Cem Concr Res. 2009; 39: 54-64.

[53] Zhongwei W, Huizhen L. High Performance Concrete. Beijing: China Railway Publishing Company; 1999. p. 49-50.

[54] Xin W, Xunyan T, Yansheng Y, Yu Z. Analysis on Toughening Mechanisms of Ceramic Nano-Composites. J Ceram 2000; 2: 107-11. in Chinese.

[55] Xijun W, Mingwen Z. Properties and Interfacial Microstructures for Nanostructured Materials. Chin J Atomic Mol Phys 1997; 2: 148-52. in Chinese. 